\title{
Quarterly Management Document - FY18, 1st Quarter, Physics-based Creep Simulations of Thick Section Welds in High Temperature and Pressure Applications
}

\author{
Thomas M. Lillo
}

January 2018

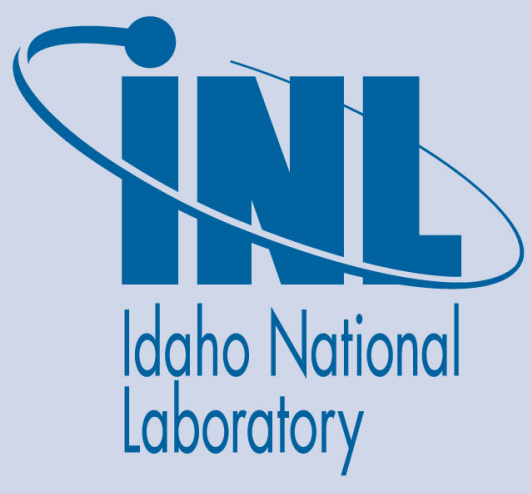

The INL is a U.S. Department of Energy National Laboratory operated by Battelle Energy Alliance 


\title{
Quarterly Management Document - FY18, 1st Quarter, Physics-based Creep Simulations of Thick Section Welds in High Temperature and Pressure Applications
}

\author{
Thomas M. Lillo
}

January 2018

Idaho National Laboratory Idaho Falls, Idaho 83415

http://www.inl.gov

Prepared for the U.S. Department of Energy

Office of Fossil Energy Under DOE Idaho Operations Office

Contract DE-AC07-05ID14517 
Quarterly Management Document - FY18, $1^{\text {st }}$ Quarter, Physics-based Creep Simulations of Thick Section Welds in High Temperature and Pressure Applications

Document \# INL/EXT-18-44376

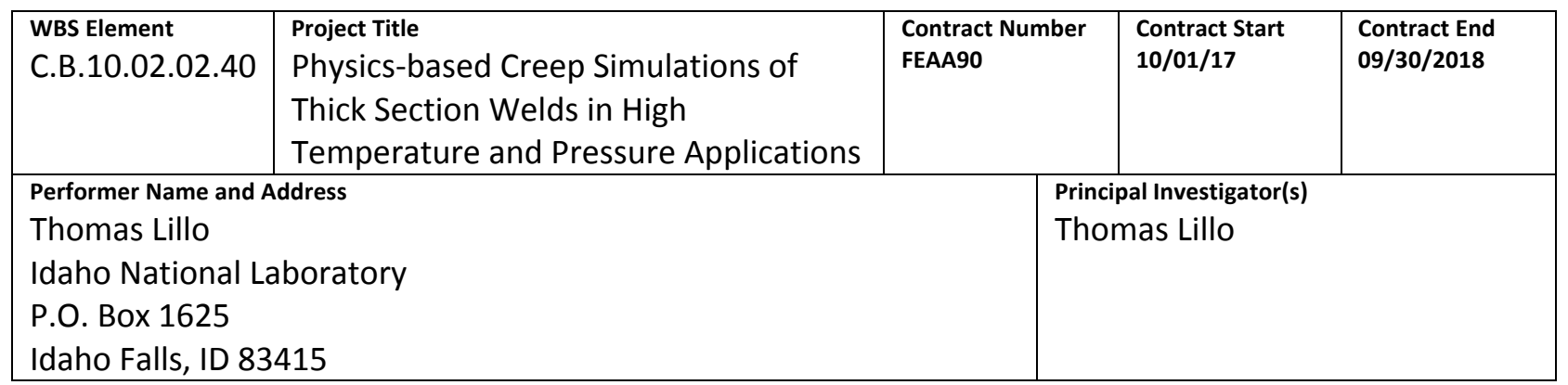

\section{BUDGET AND COST REPORT}

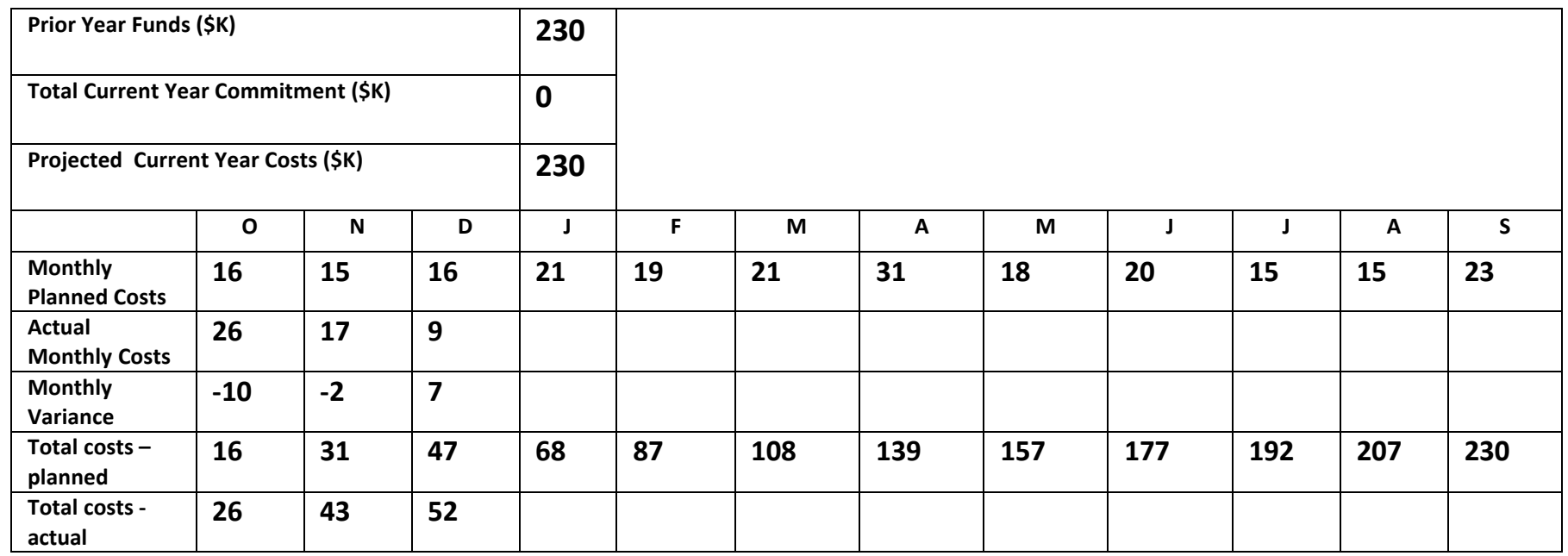

MILESTONE REPORT

\begin{tabular}{|c|l|c|c|c|}
\hline $\begin{array}{c}\text { Milestone } \\
\text { Designation }\end{array}$ & Milestone Description & Due Date & $\begin{array}{c}\text { Revised Due } \\
\text { Date }\end{array}$ & $\begin{array}{c}\text { Completion } \\
\text { Date }\end{array}$ \\
\hline A & Evaluate current MOOSE capabilities & $09 / 30 / 2015$ & $09 / 30 / 2015$ \\
\hline B & Complete Alloy 617 weld characterization & $10 / 30 / 2015$ & & $11 / 18 / 2015$ \\
\hline C & Receipt of Alloy 740H plates & $10 / 30 / 2015$ & & $11 / 05 / 2015$ \\
\hline D & Complete welds in Alloy 740H & $11 / 16 / 2015$ & $7 / 31 / 2016$ & $7 / 31 / 2016$ \\
\hline
\end{tabular}




\begin{tabular}{|c|l|l|l|l|}
\hline E & Characterize Alloy 740H welds & $02 / 01 / 2016$ & $09 / 30 / 2016$ & $9 / 02 / 2016$ \\
\hline F & Creep model development - Stage 1 & $09 / 30 / 2016$ & & $9 / 30 / 2016$ \\
\hline G & Creep Model Development - Stage 2 & $8 / 29 / 2017$ & $3 / 30 / 2018$ & \\
\hline H & Calibration of Secondary creep & $9 / 30 / 2017$ & $04 / 30 / 2018$ & \\
\hline I & Stress Drop Tests & $2 / 01 / 2017$ & $3 / 30 / 2018$ & \\
\hline J & $\begin{array}{l}\text { Characterization of creep failure } \\
\text { mechanisms }\end{array}$ & $4 / 01 / 2017$ & $04 / 30 / 2018$ & \\
\hline K & Secondary creep calibration for welds & $5 / 30 / 2018$ & & \\
\hline L & $\begin{array}{l}\text { Creep model development - Completion of } \\
\text { Stage 3 }\end{array}$ & $8 / 30 / 2018$ & & \\
\hline M & $\begin{array}{l}\text { Creep simulation of a welded joint in Alloy } \\
740 H\end{array}$ & $9 / 30 / 2018$ & & \\
\hline N & $\begin{array}{l}\text { Validation of creep simulation model via an } \\
\text { Alloy 740H weld consisting of refined } \\
\text { microstructure }\end{array}$ & $9 / 15 / 2018$ & & \\
\hline
\end{tabular}

TECHNICAL HIGHLIGHTS

Milestone G, "Creep Model Development - Stage 2"

Not all the objectives of this task were attained during FY17 and these remaining objectives will be finished in FY18 using carryover funds (the project was underspent in FY17). The main objective that remains is to incorporate Orowan looping and dislocation/ $\gamma$ ' interactions into the creep model. The effect of the evolution of gamma prime size on the looping and/or dislocation interaction also will be included in the model. Preliminary calibration of the model will be conducted using the experiment data of Alloy 617. Additionally it is still necessary to translate experimental microstructures into a form that can be used in the modeling and simulation. The extent of weld makes serial sectioning with EBSD cost-prohibitive and the current approach is to characterize the microstructure in three orthogonal directions using EBSD and then using this information to generate "synthetic" microstructure, i.e. a microstructure that is representative of the actual microstructure with the same distributions in grain size, grain shape, orientation, etc. but not necessarily exactly the same as the experimental microstructure. The synthetic microstructure will be in a format appropriate for importing into the model and simulation environment. Investigators (D. Post-Guillen and T. Ashton, "Development of a Solid Texture Synthesis Algorithm from 2D Exemplars") at INL associated with other programs are also working on this problem and contact has been made to explore common interests with regard to this issue. The expected completion date for this task has been moved to the end of March 2018.

Milestone H, "Calibration of Secondary creep"

The secondary creep rate data obtained from existing creep data on Alloy 617 from the NGNP program will be used to assess the accuracy of the model and then calibrate the model. Work on this task can only start after the dislocation $/ \gamma$ ' interaction has been incorporated into the model which is expected to be complete by midFebruary. Therefore, the completion date for this task will be moved to the end of February 2018. 


\section{Milestone I, "Stress Drop Tests"}

This task also was not completed during FY17 as originally planned due to the long duration of these tests, which are needed to quantify the creep strengthening associated with dislocation interactions with the $\gamma$ ' particle distributions at various temperatures and various $\gamma^{\prime}$ particle sizes. Specifically, the test is designed to measure the threshold stress required for dislocations to pass through the $\gamma^{\prime}$ particle dispersion. One test has been completed (Sample ID 740-SD-01-01, 750 ${ }^{\circ} \mathrm{C}$ ) while three more are in progress (740-SD-01-02, 740-SD-01-03 and 740-SD0-01), Table 1. An example of the creep curve associated with the stress drop test is shown in Figure 1. After the sample enters secondary creep the load is reduced. After the stress drop, there is a transient period where the sample does not creep. The time elapsed until the sample starts to creep again is used to determine the threshold stress according to the following the equation:

$$
\sum \Delta t=K\left(\left(\sigma_{R}-\sigma_{T}\right)^{-2}-\left(\sigma_{i}-\sigma_{T}\right)^{-2}\right) \quad \text { Eqn. } 1
$$

where

$\sum \Delta t$ is the summation of the elapsed times from previous stress drops

$\mathrm{K}$ is a kinetic constant

$\sigma_{R}$ is the remaining stress after the stress drop

$\sigma_{\mathrm{T}}$ is the threshold stress (the unknown)

$\sigma_{\mathrm{i}}$ is the initial stress at the start of the test

The equation is non-linear and a non-linear solver is used to determine both $\mathrm{K}$ and $\sigma_{\mathrm{T}}$. Test 740-SD-01-01 at $750^{\circ} \mathrm{C}$ and an initial stress of $305 \mathrm{MPa}$ was completed during the $1^{\text {st }}$ quarter of FY18 and the determination of the threshold stress performed. The analysis yielded a threshold stress of about $67 \mathrm{MPa}$ at this temperature. This seems somewhat low since a previous project on Alloy 617, with a much lower $\gamma^{\prime}$ particle fraction $(<5 \%$ vs. $-20 \%$ for Alloy $740 \mathrm{H}$ ) found a threshold stress of $77 \mathrm{MPa}$. However, it is not known at this time whether the $\gamma^{\prime}$ particle size was larger than that in the Alloy 617 test, which could possibly account for the lower threshold stress in Alloy $740 \mathrm{H}$ at this temperature. An alternate method (the Lagneborg-Bergman analysis of minimum creep rates, Met. Sci., 1976, vol. 10, pp. 20-28) for determining the threshold stress value from the existing stress drop data will be performed in the next quarter to verify the result found here by the Henderson-McLean method, (P.J. Henderson and M. McLean: Acta Metall., 1983, vol. 31, pp. 1203-19).

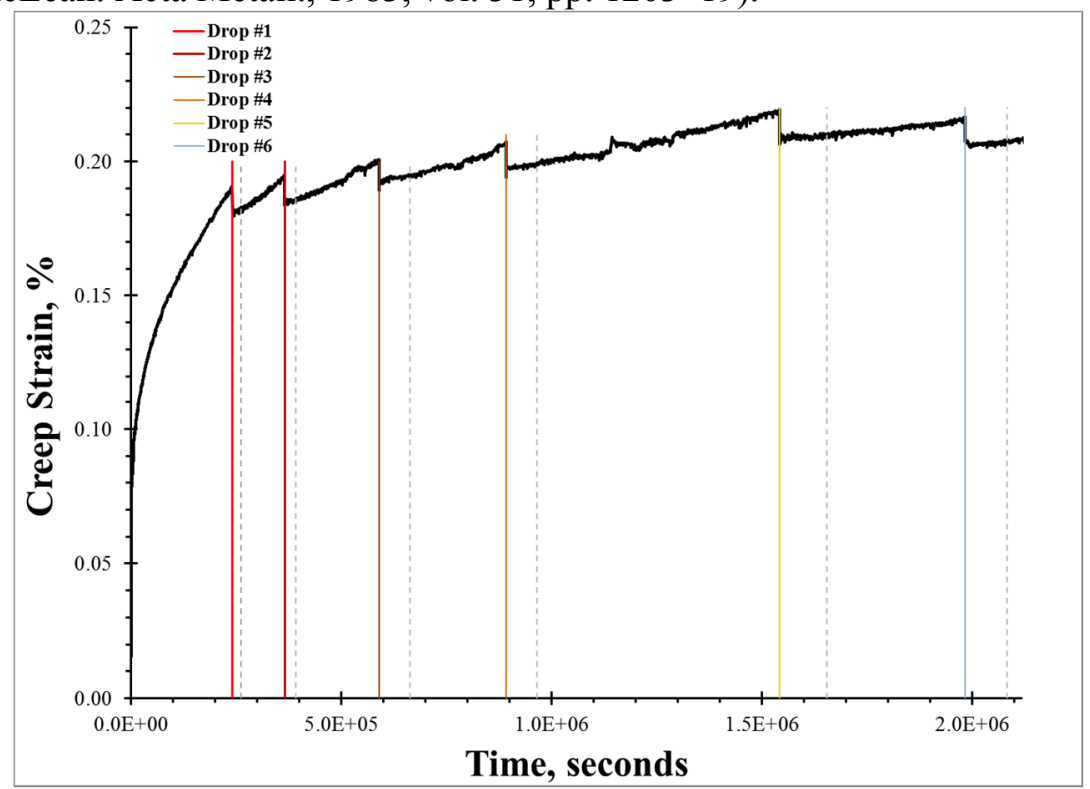

Figure 1. Creep curve for the stress drop test associated with sample 740-SD-01-03. The stress is periodically drop after the creep curve enters secondary creep. The time elapsed until the sample starts to creep again is used to determine the threshold stress. 


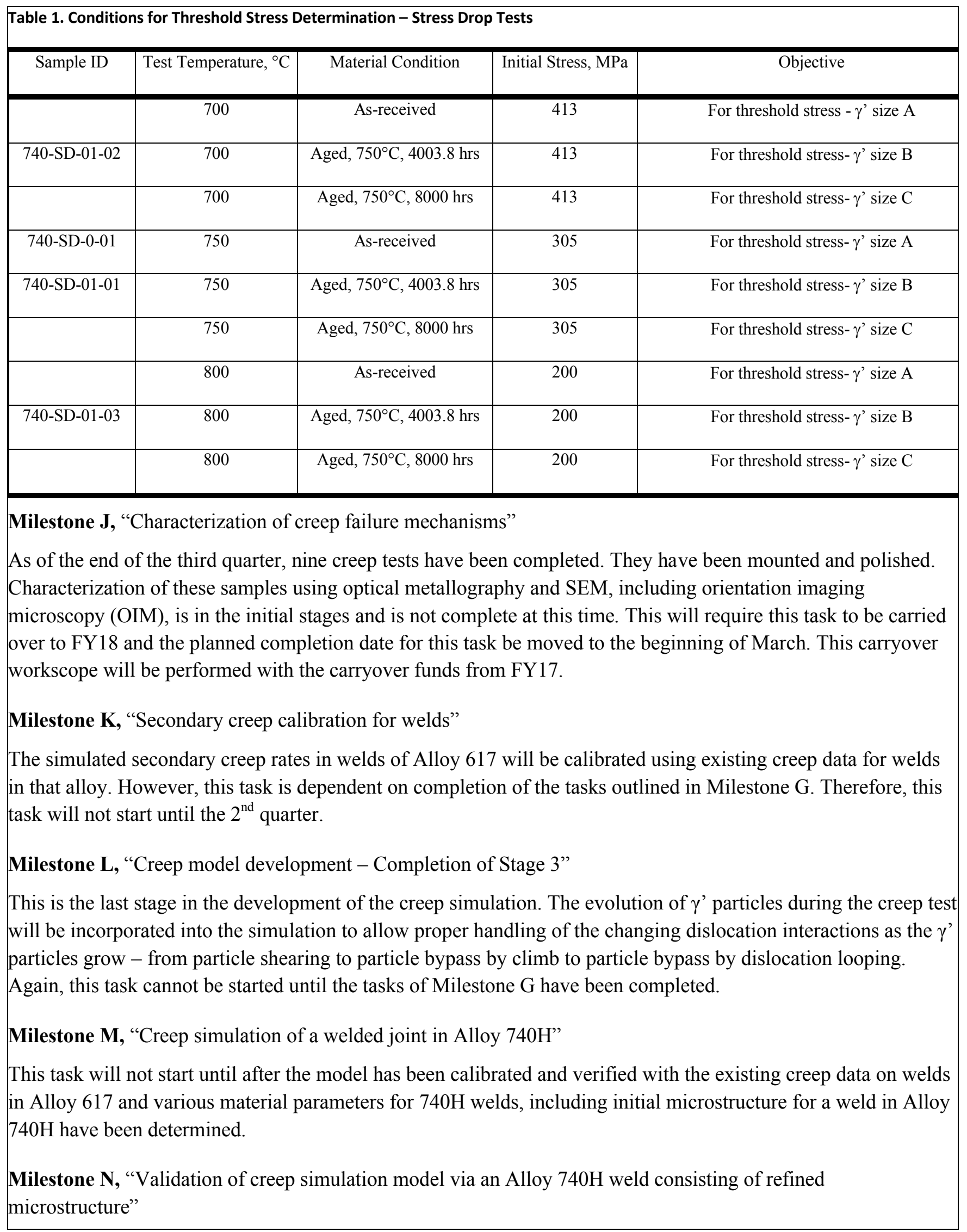


This task is designed to test/validate the model against welds with a finer grain size. The emerging technique of hybrid laser-arc welding offers the potential of greatly increased productivity with an additional decrease in the grain size of welds. To explore the validity of the model, a state-of-the-art hybrid laser arc welding system is being prepared to weld Alloy $740 \mathrm{H}$. During this quarter, existing hybrid laser arc welding equipment has been assembled and computer-controlled system checked. Trial hybrid laser arc welding runs on Alloy $740 \mathrm{H}$ will be performed early next quarter.

\section{Other highlights}

\section{$\gamma$ ' Aging Study}

Aging of welds at 700,750 and $800^{\circ} \mathrm{C}$ continues. Material aged at these temperatures for $10,000 \mathrm{hrs}$ was removed during this quarter and are being prepared for analysis of the $\gamma^{\prime}$ particle size distribution. TEM samples will be prepared from the base material, HAZ and weld metal and observed in the TEM at the Center for Advanced Energy Studies (CAES) in the next quarter. TEM samples of other material aged for lower durations have already been prepared by electropolishing and analyzed in the TEM. Image analysis was used to determine the $\gamma^{\prime}$ size distribution and the average particle size as a function of aging time. The results for aging weld metal at $750^{\circ} \mathrm{C}$ have been plotted along with the $\gamma^{\prime}$ particle size data for aging of Alloy 617 base metal that was obtained in a previous project. From these preliminary results it appears that the $\gamma^{\prime}$ particle growth behavior is virtually the same as that found for Alloy 617 at an aging temperature of $750^{\circ} \mathrm{C}$. The main difference is the size of the error bars which are considerably larger on the $740 \mathrm{H}$ weld metal data. However, the data for Alloy 617 was obtained from base metal samples. Non-equilibrium cooling in the weld metal of Alloy $740 \mathrm{H}$ resulted in macrosegregation and variation in the local composition. This variation in composition likely is responsible for local variations in $\gamma^{\prime}$ precipitation and growth behavior, ultimately resulting in a wider variation in $\gamma^{\prime}$ particle size in weld material compared to base metal which has a more uniform composition throughout. Analysis of Alloy $740 \mathrm{H}$ base metal aged at $750^{\circ} \mathrm{C}$ will be analyzed and added to the plot of Figure 2 . The average $\gamma$ ' size data for base, HAZ and weld materials aged at other temperatures and times will also be added to the plot in Figure $\mathbf{2}$ as the analyses are completed. 


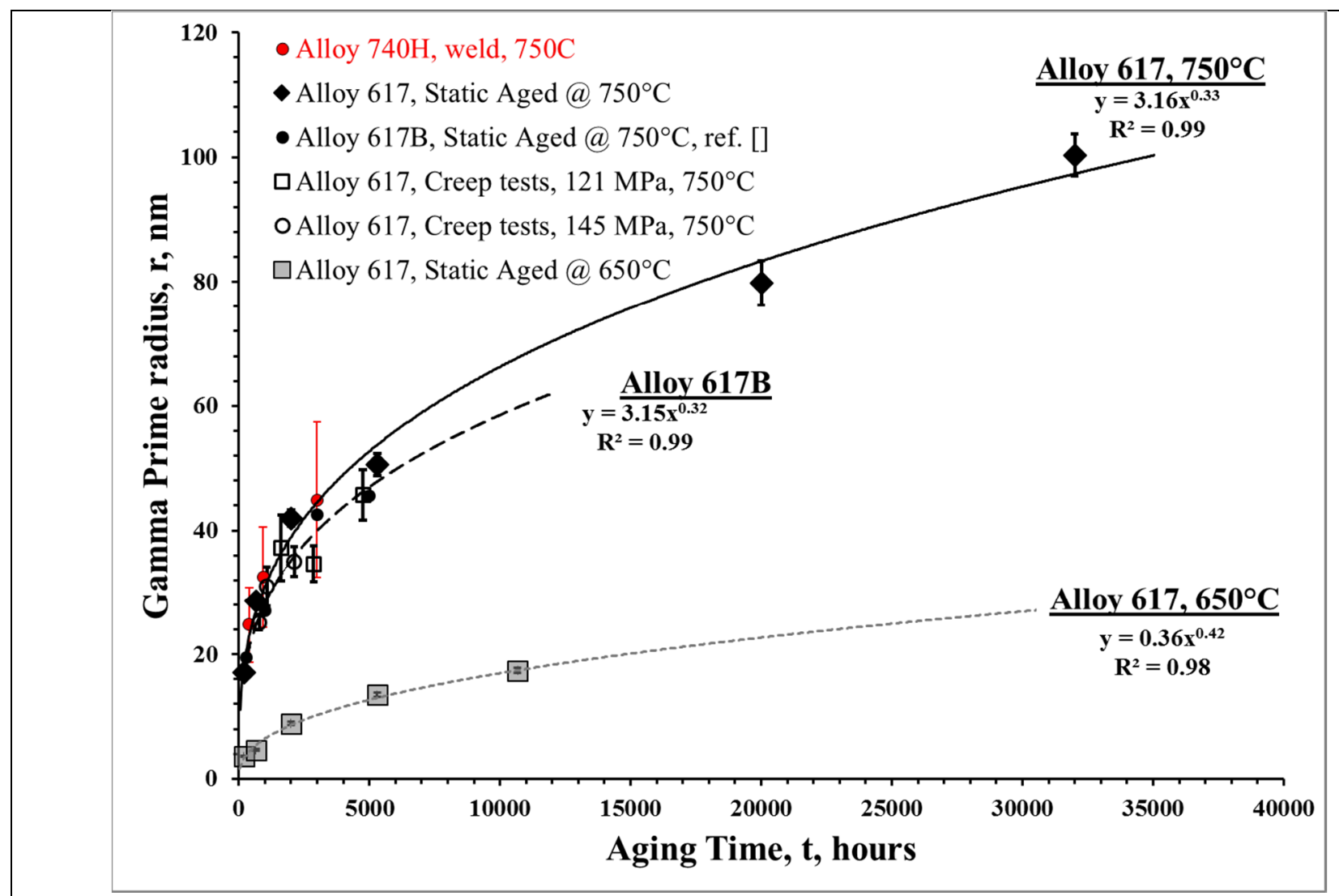

Figure 2. Growth characteristics of $\gamma^{\prime}$ in Alloy $740 \mathrm{H}$ weld metal have been plotted with $\gamma^{\prime}$ growth behavior found in the base metal of Alloy 617. Aging temperature for the Alloy $740 \mathrm{H}$ weld metal was $750^{\circ} \mathrm{C}$.

\section{ISSUES}

Both the modeling effort and the experimental data acquisition and characterization fell behind schedule in FY17 and under budget. Although some ground was made up during the first quarter of FY18 the project remains behind schedule but the remaining funds still appear to be sufficient to complete the remaining tasks.

\begin{tabular}{|l|l|}
\hline Report Prepared By & Date \\
\hline Thomas M. Lillo & $01 / 23 / 2018$ \\
\hline
\end{tabular}

